Masahiro Fujimoto $\cdot$ Piranit Nik Kantaputra

Shiro Ikegawa $\cdot$ Yoshimitsu Fukushima $\cdot$ Shin-ichi Sonta

Masafumi Matsuo • Takafumi Ishida • Tadashi Matsumoto

Shinji Kondo · Hiroaki Tomita $\cdot$ Han-Xiang Deng

Michele D'urso • Maria Michela Rinaldi • Valerio Ventruto

Toshihisa Takagi $\cdot$ Yusuke Nakamura $\cdot$ Norio Niikawa

\title{
The gene for mesomelic dysplasia Kantaputra type is mapped to chromosome 2q24-q32
}

Received: November 27, 1997 / Accepted: December 5, 1997

\begin{abstract}
Mesomelic dysplasia Kantaputra type (MDK) (MIM *156232) is a new autosomal dominant skeletal dysplasia characterized by dwarfism, shortening of the fore-
\end{abstract}

M. Fujimoto $(\varangle) \cdot$ S. Kondo $\cdot$ H. Tomita $\cdot$ N. Niikawa

Department of Human Genetics, Nagasaki University School of

Medicine, 1-12-4 Sakamoto, Nagasaki 852, Japan

Tel. +81-958-49-7120; Fax +81-958-49-7121

e-mail: f1144@cc.nagasaki-u.ac.jp

\section{Fujimoto}

Second Department of Surgery, Nagasaki University School of

Medicine, Nagasaki, Japan

P.N. Kantaputra

Department of Pediatric Dentistry, School of Dentistry, Chiang Mai University, Thailand

S. Ikegawa $\cdot$ T. Takagi $\cdot$ Y. Nakamura

Human Genome Center, Institute of Medical Science, University of

Tokyo, Tokyo, Japan

Y. Fukushima

Department of Hygiene and Medical Genetics, Shinshu University School of Medicine, Matsumoto, Japan

S. Sonta

Department of Genetics, Institute for Developmental Research,

Aichi Human Service Center, Kasugai, Japan

M. Matsuo

Division of Genetics, ICMR, Kobe University, Kobe, Japan

T. Ishida

Department of Biological Sciences, Graduate School of Science,

University of Tokyo, Tokyo, Japan

\section{T. Matsumoto}

Department of Pediatrics, Nagasaki University School of Medicine, Nagasaki, Japan

S. Kondo

Department of Plastic and Reconstructive Surgery, Nagasaki

University School of Medicine, Nagasaki, Japan

H.-X. Deng

Neurogenetic Laboratory, Department of Neurology, Northwestern University Medical School, Chicago, IL, USA

M. D'urso · V. Ventruto

Istituto Internazionale di Genetica e Biofisica-Area di Ricerca

C.N.R., Napoli, Italy

M.M. Rinaldi

Servizio di Genetica Medica Ospedale A. Cardarelli, Napoli, Italy arms/lower-legs, carpal/tarsal synostosis, and dorsolateral foot deviation. We studied a Thai family in which 15 members in 3 generations were affected with MDK. With reference to the breakpoints of a balanced translocation $[\mathrm{t}(2 ; 8)(\mathrm{q} 31 ; \mathrm{p} 21)]$ in patients from a previously reported Italian family with a skeletal dysplasia that appears similar to MDK, a linkage analysis was performed in the Thai family using 50 CA-repeat markers mapped to nearby regions (2q22-q34 and 8p24-p21) of the translocation breakpoints. The results clearly ruled out a linkage of MDK to marker loci at the 8p24-p21 region, whereas all nine affected members available for the study shared a haplotype at four loci $(D 2 S 2284, D 2 S 326, D 2 S 2188$, and $D 2 S 2314$ ) spanning about $22.7 \mathrm{cM}$ in the $2 \mathrm{q} 24-\mathrm{q} 32$ region. The computer-assisted two-point linkage analysis revealed maximum logarithm of odds (lod) scores of 4.82, 4.21, 4.82, and $4.21(\theta=0)$ at these loci, respectively. These data indicated that the MDK locus is in the vicinity of D2S2284 and $D 2 S 2188$ loci that are most likely mapped to $2 \mathrm{q} 24-\mathrm{q} 32$.

Key words Mesomelic dysplasia Kantaputra type - CArepeat marker · Linkage analysis - Logarithm of odds (lod) score $\cdot$ Haplotype analysis $\cdot$ Human HOXD genes

\section{Introduction}

Mesomelic dysplasia, a heterogeneous group of hereditary skeletal dysplasias, is characterized by dwarfism due to disproportionate shortness of the middle segment of the limb. It is classified into 5 groups: Nievergelt type, Langer type, Robinow type, Reinhardt type, and others (Milgram 1990). Kantaputra et al. (1992) described a Thai family with a new type of mesomelic dysplasia. Many members of the family had shortening of the ulna/radius/fibula, bowing of the radius, synostosis between the tibia and fibula and in carpal/ tarsal bones, and small malformed calcaneus/talus, and walked on their toe-tips with dorsolateral foot deviation. The deformities of the radius and ulna somewhat resemble those of Langer-type mesomelic dysplasia, but otherwise 
the condition in the family was distinct. The family disease was inherited in an autosomal dominant fashion (Kantaputra et al. 1992).

Another type of skeletal dysplasia was reported by Ventruto et al. (1983). The disease in this Italian family is characterized by multiple skeletal abnormalities involving shortening of the forearm, bowing of the radius, Madelung deformity, cubitus valgus with limited movement, fusion between the $\mathrm{C} 1$ and $\mathrm{C} 2$ vertebrae, and cleft L5 and S1 (Ventruto et al. 1983). Interestingly, all four affected individuals in two generations had a balanced reciprocal translocation $[\mathrm{t}(2 ; 8)(\mathrm{q} 31 ; \mathrm{p} 21)]$, and this translocation was not seen in any other unaffected family members (Ventruto et al. 1983). Thus, the putative disease gene may be located to either of the breakpoints. The clinical and radiological similarity of the diseases in the Thai and Italian families suggested that they are allelic, although the condition in the latter family was much less severe. Here, we report the results of a linkage analysis in the Thai family, based on the "allelism" hypothesis and focusing upon the breakpoint regions of the translocation in the Italian family.

\section{Materials and methods}

Family study

The Thai family examined in this study consists of 63 members in four generations, among which 15 members are affected with MDK (Figs. 1,2). The disorder started from a pair of male twins (II-5 as a proband, and II-8) in the second generation of the family. The twins were said to be monozygotic. As none of their parents and siblings had the disease, it was most likely that the twins were fresh mutants. Of the 15 affected individuals, 10 were males and 5 females (a sex ratio of 2:1). Of a total of 25 third- and fourth-generation members, 13 were affected (segregation ratio $0.52 \pm 0.001$, calculated by the complete ascertainment method), and the disease was transmitted from the proband to every lower generation without skipping. These findings are consistent with an autosomal dominant inheritance with complete penetrance. Of the 63 members, 21 were examined clinically by one of us (PNK). A detailed family history was obtained through personal interviews with available family members. After obtaining informed consent, anticoagulated blood samples were taken from 9 affected members and 13 unaffected members or their spouses (Fig. 2). Their lymphocytes were established as Epstein-Barr virus transformed lymphoblastoid cell lines. These samples were stored in liquid nitrogen until use.

DNA extraction and marker analysis

High-molecular-weight genomic DNA was extracted from the lymphoblastoid cell lines by the standard method. Fifty polymorphic microsatellite (CA-repeat) markers were selected from the Généthon collections (Dib et al. 1996). The markers consisted of $24 \mathrm{CA}$ repeats mapped to $2 \mathrm{q} 22-\mathrm{q} 34$ and $26 \mathrm{CA}$ repeats assigned to $8 \mathrm{p} 24-\mathrm{p} 21$, which correspond to nearby regions of the $\mathrm{t}(2 ; 8)(\mathrm{q} 31 ; \mathrm{p} 21)$ breakpoints in the Italian family with skeletal dysplasia (Ventruto et al. 1983).

Genotypes of the family members for each marker locus were determined using the DNA-sequencer-assisted method with fluorescent microsatellite marker DNAs (Mansfield et al. 1994). Total genomic DNA from each
Fig. 1. The Thai family with mesomelic dysplasia Kantaputra type. The individuals in the front row, except the furthest right and a baby, are affected with the disease

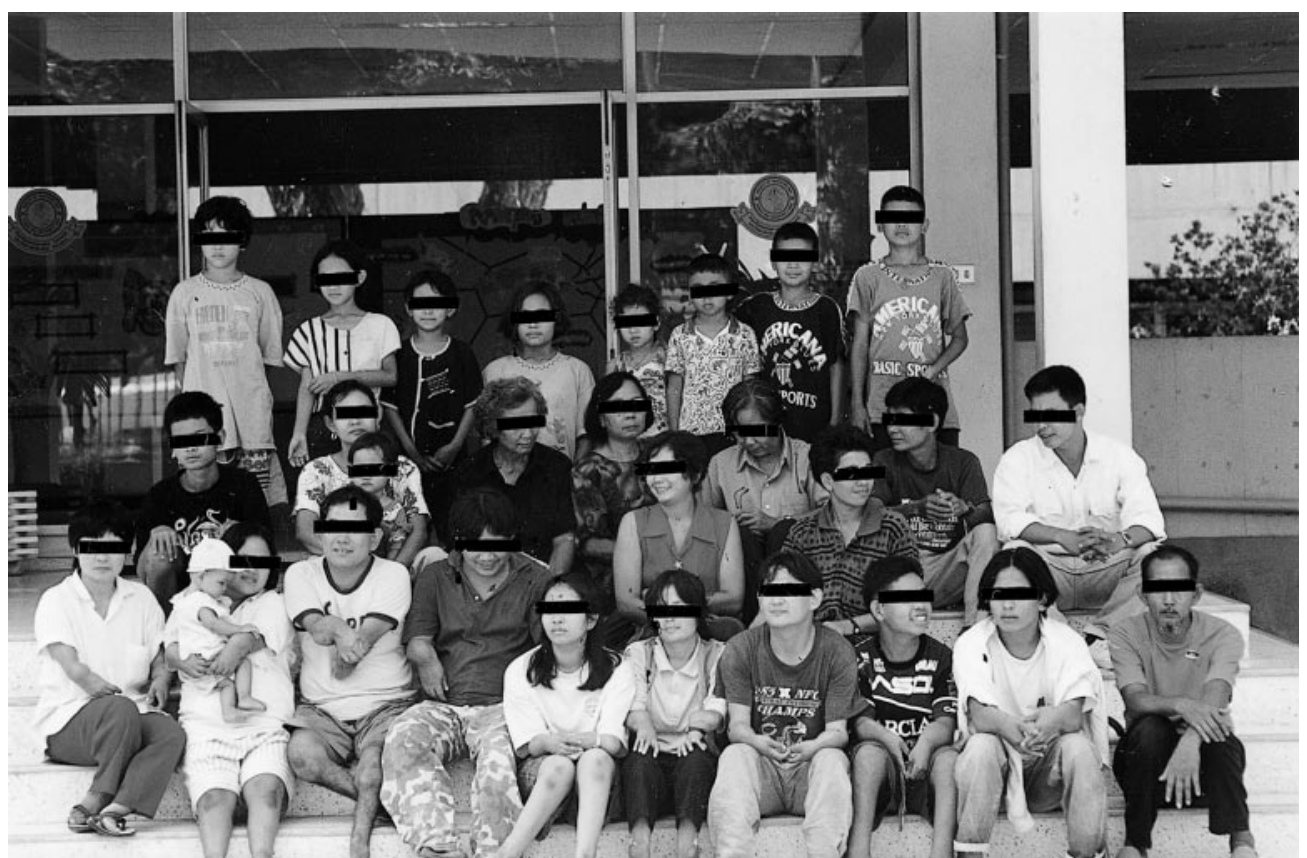




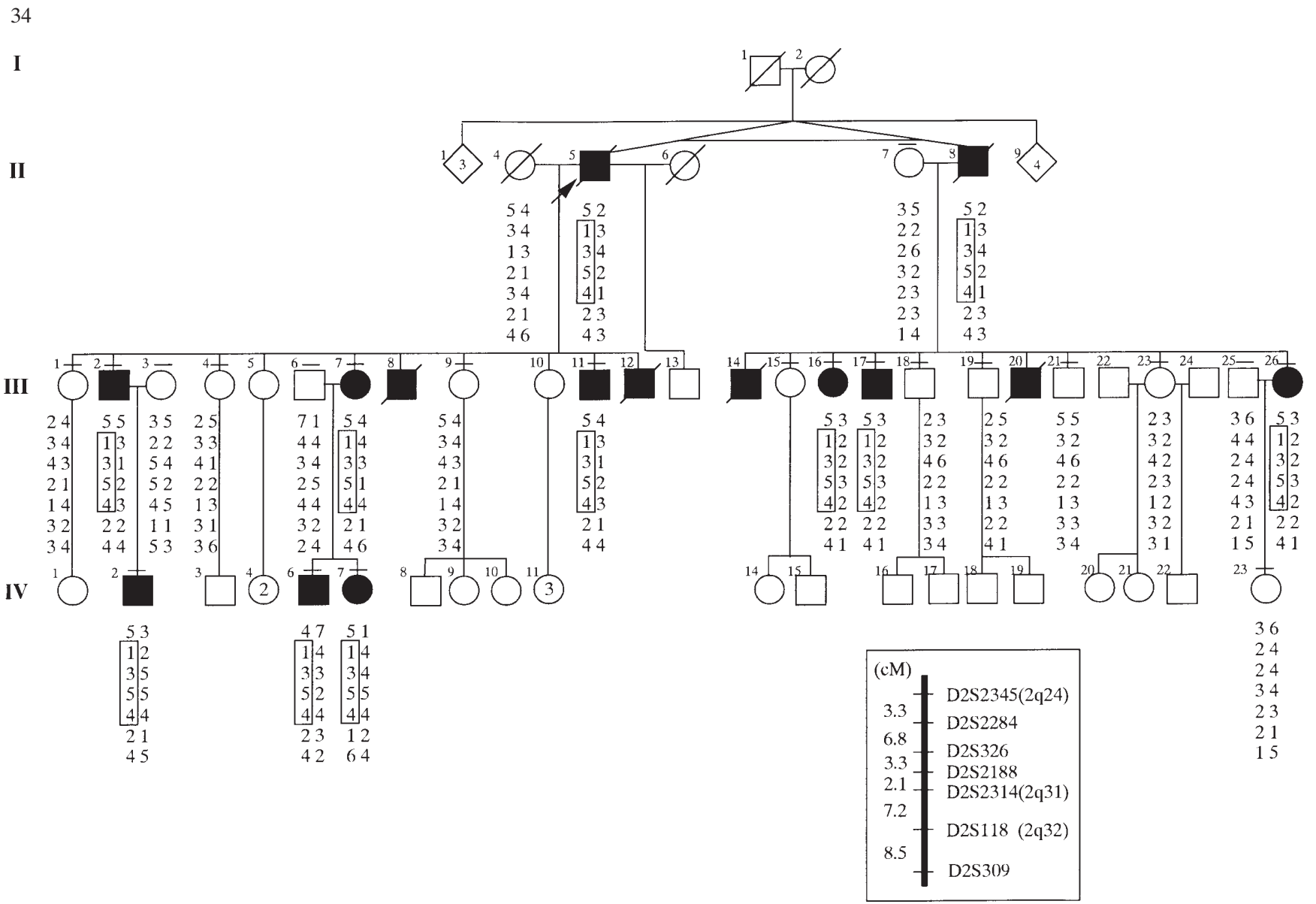

Fig. 2. Pedigree of the Thai family with haplotypes. Individuals examined are marked with short bars above their symbols. Numbers in boxes depict haplotypes common among affected members (filled symbols).
A diagonal slash signifies that the individual is dead. Squares and circles represent males and females, respectively. The inset shows the arrangement of the loci in the region examined individual was amplified by polymerase chain reaction (PCR) using primer sets for the CA-repeat makers (Dib et al. 1996) in a 10- $\mu 1$ reaction mixture containing $100 \mathrm{ng}$ genomic DNA, $1 \mu \mathrm{M}$ each of Cy5-labeled sense primer and unlabeled antisense primer, $60 \mu \mathrm{M}$ each of dNTP, $20 \mathrm{mM}$ Tris- $\mathrm{HCl}(\mathrm{pH} 8.4), 50 \mathrm{mM} \mathrm{KCl}, 1.5 \mathrm{mM} \mathrm{MgCl}_{2}$, and $0.5 \mathrm{U}$ Taq DNA polymerase. PCR was carried out in a GeneAmp PCR System 9600 (Perkin Elmer Cetus, Norwalk, CT, USA) under the following conditions: one cycle at $94^{\circ} \mathrm{C}$ for $3 \mathrm{~min}$; a further 25 cycles at $94^{\circ} \mathrm{C}$ for $30 \mathrm{~s}$ for denaturation, at $55^{\circ} \mathrm{C}$ for $30 \mathrm{~s}$ for annealing, and at $72^{\circ} \mathrm{C}$ for $30 \mathrm{~s}$ for extension; and one cycle of elongation to ensure complete extension at $72^{\circ} \mathrm{C}$ for $10 \mathrm{~min}$. A mixture containing $4 \mu \mathrm{l}$ of 10 -fold diluted PCR product, $3 \mu \mathrm{l}$ loading dye $(5 \mu \mathrm{g} / \mu \mathrm{l}$ dextran blue 2000 in deionized formamide), and $1 \mu \mathrm{l}$ each of the size markers (Cy5 Sizer, Pharmacia Biotech, Uppsala, Sweden) was made. This mixture was denatured at $90^{\circ} \mathrm{C}$ for $3 \mathrm{~min}$ and loaded on an $8 \%$ LongRanger gel (FMC BioProducts, San Jose, CA, USA) containing $7 \mathrm{M}$ urea, $90 \mathrm{mM}$ Trisborate ( $\mathrm{pH} 8.0$ ), and $2 \mathrm{mM}$ ethylenediaminetetraacetic acid (EDTA). The DNA was then electrophoresed in a running buffer containing $40 \mathrm{mM}$ Tris-borate $(\mathrm{pH} 8.0)$ and $1 \mathrm{mM}$ EDTA, using an automated DNA-sequencer (ALFexpress DNA sequencer, Pharmacia) at $55^{\circ} \mathrm{C}$ and $38 \mathrm{~W} /$ gel. The resulting data were analyzed with Fragment Manager version 1.2 software (Pharmacia), to determine genotypes for marker loci in each family member.

\section{Statistical analysis}

Family information and genotypes determined were stored in a pedigree computer program, LINKAGE 5.1 (Lathrop et al. 1984). Two-point linkage analysis was performed using the MLINK program of the LINKAGE package. Since the mutant and wild-type allele frequencies of the putative disease gene were not known, 0.00001 and 0.99999 were used as minimum and maximum values, respectively. For all the polymorphic markers, allele frequencies were kept equal. Recombination distances between the marker loci were based on the Généthon linkage map (Dib et al. 1996). Penetrance of the disease was estimated at $100 \%$ in the family.

\section{Results}

Genotypes were successfully determined in all the loci and all the 21 family members examined, and the resultant alle- 
Table 1 Two-point logarithm of odds (lod) scores between the MDK and marker loci

\begin{tabular}{|c|c|c|c|c|c|c|c|c|c|c|c|c|c|}
\hline \multirow{2}{*}{$\begin{array}{l}\text { Locus } \\
\text { symbol }\end{array}$} & \multirow{2}{*}{$\begin{array}{l}\text { Distance } \\
\text { (cM) }\end{array}$} & \multicolumn{10}{|c|}{ Lod score $(\Theta)$} & \multirow[b]{2}{*}{$\mathrm{Zmax}$} & \multirow[b]{2}{*}{$\Theta \max$} \\
\hline & & 0.00 & 0.05 & 0.10 & 0.15 & 0.20 & 0.25 & 0.30 & 0.35 & 0.40 & 0.45 & & \\
\hline D2S2345 & & $-\infty$ & 0.32 & 0.92 & 1.13 & 1.16 & 1.09 & 0.93 & 0.72 & 0.45 & 0.17 & 1.16 & 0.20 \\
\hline D2S2284 & 3.3 & 4.82 & 4.44 & 4.04 & 3.62 & 3.17 & 2.69 & 2.18 & 1.64 & 1.05 & 0.43 & 4.82 & 0.00 \\
\hline D2S326 & 6.8 & 4.21 & 3.88 & 3.53 & 3.16 & 2.76 & 2.34 & 1.89 & 1.41 & 0.89 & 0.35 & 4.21 & 0.00 \\
\hline D2S2188 & 3.3 & 4.82 & 4.44 & 4.04 & 3.62 & 3.17 & 2.69 & 2.18 & 1.64 & 1.05 & 0.43 & 4.82 & 0.00 \\
\hline D2S2314 & 2.1 & 4.21 & 3.88 & 3.53 & 3.16 & 2.76 & 2.34 & 1.89 & 1.41 & 0.89 & 0.35 & 4.21 & 0.00 \\
\hline D2S118 & 7.2 & $-\infty$ & 1.04 & 1.36 & 1.42 & 1.35 & 1.21 & 1.01 & 0.76 & 0.46 & 0.16 & 1.42 & 0.15 \\
\hline D2S309 & 8.5 & $-\infty$ & 1.61 & 1.87 & 1.88 & 1.76 & 1.56 & 1.30 & 0.98 & 0.62 & 0.23 & 1.88 & 0.15 \\
\hline
\end{tabular}

les at each locus were symbolized as numbers from 7 to 1 , according to their size. In one (8p24-p21) of the two regions analyzed, none of the alleles appeared consistently among the affected members, the region thereby being ruled out from a linkage to the disease locus (data not shown). On the other hand, all of the nine affected members available for this study seemed to share a 1-3-5-4 haplotype at the D2S2284, D2S326, D2S2188, and D2S2314 loci in the 2q22q34 region (Fig. 2). The computer-assisted two-point linkage analysis revealed maximum logarithm of odds (lod) scores of $4.82,4.21,4.82$, and $4.21(\theta=0)$ at these loci, respectively (Table 1 ). Haplotype analysis suggested that the MDK locus is localized between the D2S2345 and D2S118 loci with a genetic distance of $22.7 \mathrm{cM}$, since there were no recombinations in a $D 2 S 2284-D 2 S 326-D 2 S 2188$ D2S2314 interval, while a recombination was observed between D2S2345 and D2S2284 in IV-6 and between D2S2314 and D2S118 in IV-7, respectively (Fig. 2). Haplotypes of the proband and his twin-brother were deduced from those in their children and grandchildren. As the four marker loci correspond to 2q24-q32 (Dib et al. 1996; the CHLC map, version 4: http://www.chlc.org), our study indicates that the disease locus is mapped to the region.

\section{Discussion}

The strategy for our linkage analysis was based on the assumption that MDK in the Thai family (Kantaputra et al. 1992 ) is allelic to the disease in the Italian family (Ventruto et al. 1983). This candidate positional approach was successful and provided evidence that the MDK locus is confined to a segment between the D2S2345 and D2S118 loci. However, the results of our linkage analysis do not necessarily rule out the possibility that the disease locus accidentally corresponds to the $2 \mathrm{q} 31$ breakpoint region in the Italian patients. Further study is necessary to confirm this. Moreover, it is of interest to know whether other mesomelic dysplasia loci are mapped to the same region.

The genomic region, 2q24-q32 (most likely $2 \mathrm{q} 31$ ), to which the MDK locus was assigned in the present study, is the human HOXD gene cluster region (Apiou et al. 1996). Products of these genes act as transcription factors (Gehring et al. 1990), and are essential for the proper embryonic development of structures along the trunk and limb axes (Krumlauf 1992). In addition, the $5^{\prime}$-regions of the HOXA and HOXD genes, related to the Drosophila gene, Abdominal B, act coordinately to control the growth and morphogenesis of skeletal structures along the proximodistal axis of developing limbs (Dollé et al. 1989; Yokouchi et al. 1991; Haack and Gruss 1993). It has recently been demonstrated that some limb abnormalities are associated with Hoxd gene mutations in vertebrates including the human. An example is the shortening or absence of the radius and ulna observed in Hoxa11/Hoxd11 double homozygous mutants in the mouse (Davis et al. 1995). Human synpolydactyly type II syndrome as an autosomal dominant trait is caused by heterozygous mutation in HOXD13 (Muragaki et al. 1996). Therefore, the human $H O X D$ genes, especially those located at the 5 '-region of the gene cluster, are strong candidates for the gene responsible for the MDK phenotype.

Acknowledgments We express our gratitude to all the members of the Thai and the Italian families. We also thank Dr. Lai Poh-San for her efforts in searching for a patient living in Singapore, Dr. Osamu Miyoshi, Dr. Masayuki Egashira, Dr. Nobutomo Miwa, Dr. Kohki Yamada, Ms. Hiroko Iwaki Ms. Keiko Wakui, and Mr. Naoki Harada for their technical assistance. This work was supported in part by a grant-in-aid for Scientific Research A (No. 08307019) from the Ministry of Education, Science, Sport and Culture of Japan.

\section{References}

Apiou F, Flagiello D, Cillo C, Malfoy B, Poupon MF, Dutrillaux B (1996) Fine mapping of human $H O X$ gene clusters. Cytogenet Cell Genet 73:114-115

Davis AP, Witte DP, Hsieh-Li HM, Potter SS, Capecchi MR (1995) Absence of radius and ulna in mice lacking hoxa-11 and hoxd-11. Nature 375:791-795

Dib C, Fauré S, Fizames C, Samson D, Drouot N, Vignal A, Millasseau P, Marc S, Hazan J, Seboun E, Lathrop M, Gyapay G, Morissette J, Weissenbach J (1996) A comprehensive genetic map of the human genome based on 5264 microsatellites. Nature 380:152-154

Dollé P, Izpisúa-Belmonte JC, Falkenstein H, Renucci A, Duboule D (1989) Coordinate expression of the murine Hox-5 complex homeobox-containing genes during limb pattern formation. Nature 342:767-772

Gehring WJ, Müller M, Affolter M, Percival-Smith A, Billeter M, Qian YQ, Otting G, Wüthrich K (1990) The structure of the homeodomain and its functional implications. Trends Genet 6:323329

Haack H, Gruss P (1993) The establishment of murine Hox-1 expression domains during patterning of the limb. Dev Biol 157:410422 
Kantaputra PK, Gorlin RJ, Langer LO Jr (1992) Dominant mesomelic dysplasia, ankle, carpal, and tarsal synostosis type: A new autosomal dominant bone disorder. Am J Med Genet 44:730-737

Krumlauf R (1992) Evolution of the vertebrate Hox homeobox genes. Bioessays 14:245-252

Lathrop GM, Lalouel JM, Julier C, Ott J (1984) Strategies for multilocus linkage analysis in humans. Proc Natl Acad Sci USA 81: 3443-3446

Mansfield DC, Brown AF, Green DK, Carothers AD, Morris SW, Evans JH, Wright AF (1994) Automation of genetic linkage analysis using fluorescent microsatellite markers. Genomics 24:225-233

Milgram JW (1990) International nomenclature of constitutional disease of bone, 1990. In: Milgram JW (ed) Radiologic and histologic pathology of nontumorous disease of bones and joints. Northbrook, Lake Forest, pp 92-94

Muragaki Y, Mundlos S, Upton J, Olsen BR (1996) Altered growth and branching patterns in synpolydactyly caused by mutations in HOXD13. Science 272:548-551

Ventruto V, Pisciotta R, Renda S, Festa B, Rinaldi MM, Stabile M, Cavaliere ML, Esposito M (1983) Multiple skeletal familial abnormalities associated with balanced reciprocal translocation 2;8(q32;p13). Am J Med Genet 16:589-594

Yokouchi Y, Sasaki H, Kuroiwa A (1991) Homeobox gene expression correlated with the bifurcation process of limb cartilage development. Nature 353:443-445 